\title{
BNREL
}

Transforming ENERGY

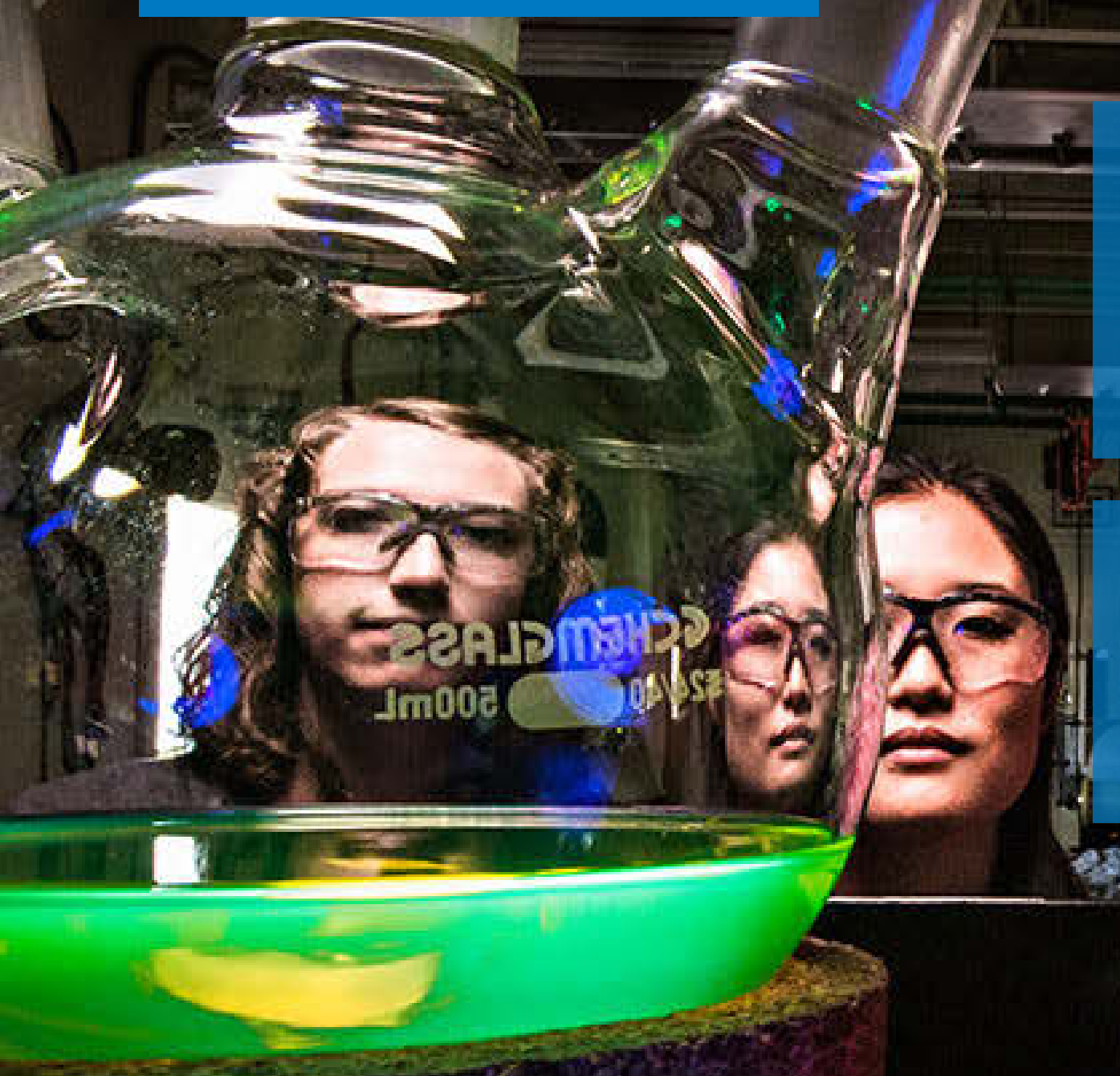

\section{PTC and ITC for Aviation Fuel: Analysis Using the Biomass Scenario Model}

Emily Newes and Laura Vimmerstedt (NREL) Zia Haq and Alicia Lindauer (DOE) March 5, 2021 


\section{Disclaimer}

- Sources and limitations of information/data used in analysis:

- The analysis is based on projections, estimates or assumptions made on a best-effort basis, based upon expectations of current and future conditions at the time they were developed.

- The analysis was prepared with information available at the time the analysis was conducted. Analysis results could be different if new information becomes available and is incorporated.

- Limitations on what analysis results should be used for:

- This analysis was conducted to meet an immediate need and was based on the best information available within timing constraints.

- This analysis is a starting point for additional research and consideration of investment or policy options. Other factors that can inform decision-making are not considered here.

○ The analysis results are not intended to be the sole basis of investment, policy, or regulatory decisions.

- Analysis based on application of specific NREL tools: This analysis was conducted using the NREL Biomass Scenario Model (BSM https://www.nrel.gov/analysis/bsm/). BSM is a system dynamics model of the bioenergy supply chain that focuses on how the bioenergy industry could develop over time, given feedbacks in the system and scenario assumptions.

This work was authored in part by the National Renewable Energy Laboratory, operated by Alliance for Sustainable Energy, LLC, for the U.S. Department of Energy (DOE) under Contract No. DE-AC36-08G028308. Funding provided by U.S. Department of Energy Office of Energy Efficiency and Renewable Energy bioenergy Technologies Office. The views expressed herein do not necessarily represent the views of the DOE or the U.S. Government. 


\section{Jet Fuel Consumption and GHG Emissions}

- Total jet fuel consumption is estimated to increase annually by $1.8 \%$ through 2040 .

- The aviation sector is difficult to decarbonize primarily because of fuel energy density requirements and safety standards.

- Sustainable aviation fuel is a currently available option for decreasing emissions.

\begin{tabular}{|c|c|}
\hline & Total Estimated Jet Fuel Consumption (million gallons)* \\
\hline 2019 & 23,521 \\
\hline 2025 & 26,105 \\
\hline 2030 & 28,248 \\
\hline 2035 & 30,416 \\
\hline 2040 & 32,551 \\
\hline
\end{tabular}

*Forecast was published before COVID pandemic and does not incorporate potential associated impacts on air travel.

Source: "FAA Aerospace Forecasts," https://www.faa.gov/data research/aviation/aerospace forecasts/

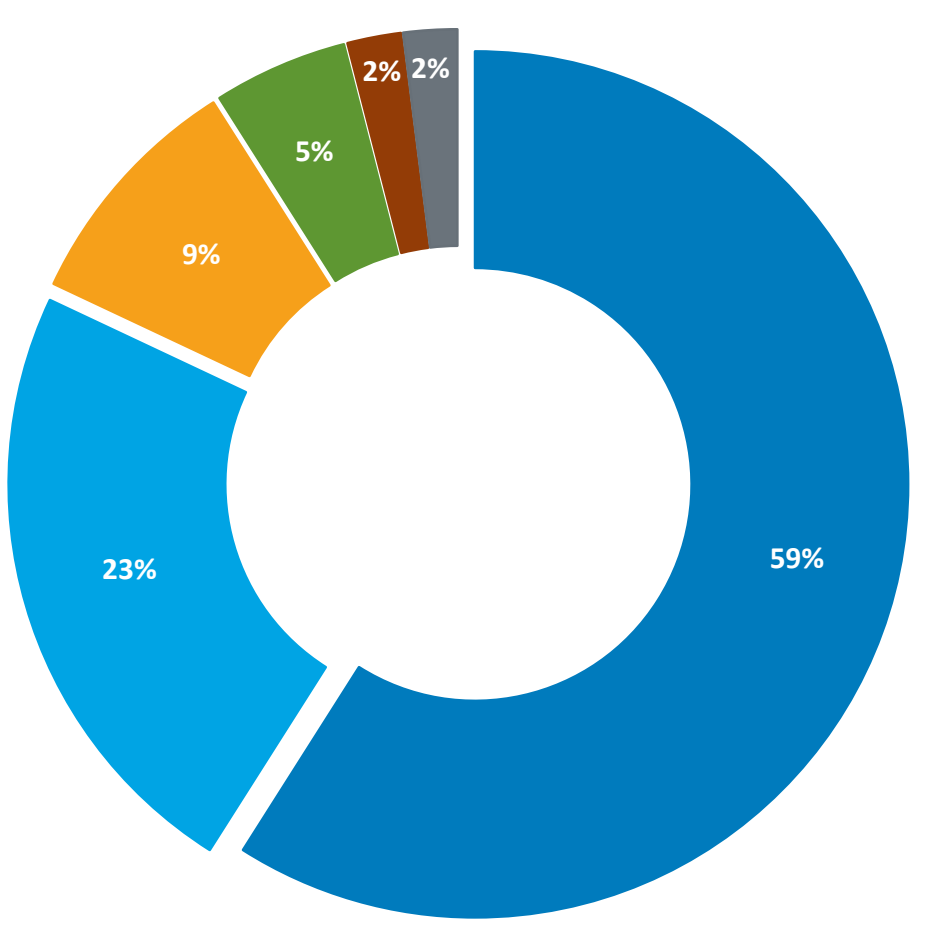

Light-duty vehicles

Medium- and heavyduty vehicles

Aircraft

Other

Rail

Ships and boats

Source: "Fast Facts on Transportation Greenhouse Gas Emissions," https://www.epa.gov/greenvehicles/fast-facts-transportation-greenhouse-gas-emissions

- The U.S. transportation sector contributes $28 \%$ of greenhouse gas (GHG) emissions.

- Of the $28 \%$, aviation accounts for $9 \%$ of GHG emissions. 


\section{Analysis Questions}

- What are the possible sustainable aviation fuel (SAF) implications of different policy mechanisms?

- What is the potential cost of these policies?

-What are the potential associated decreases in carbon dioxide $\left(\mathrm{CO}_{2}\right)$ emissions?

For this analysis, we will focus on an investment tax credit (ITC) and a production tax credit (PTC). 
Methodology 


\section{The BSM models the bioeconomy.}

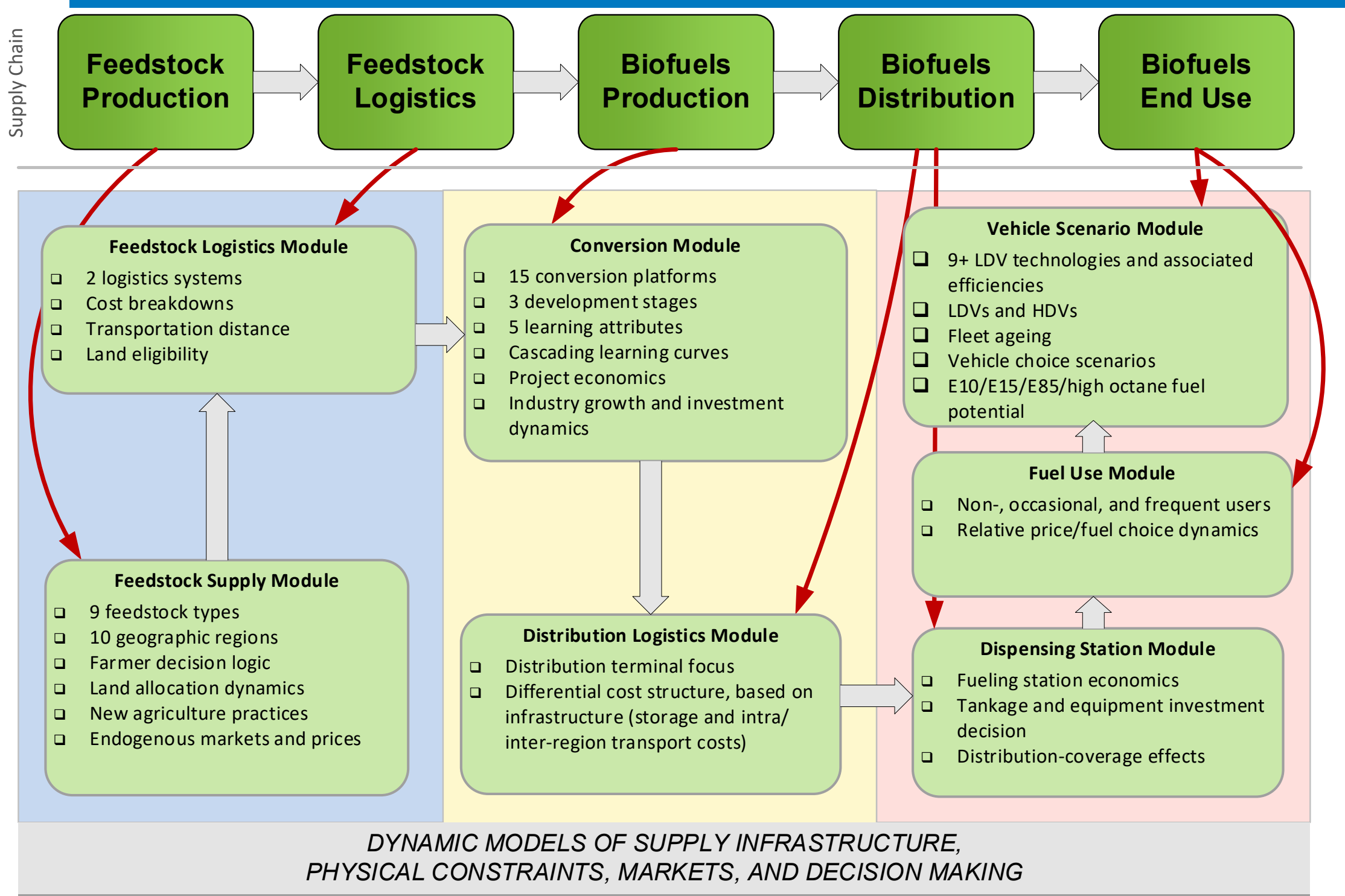

We use the Biomass

Scenario Model (BSM) to simulate the potential implications of different policy scenarios.

In this analysis, we focus on potential SAF production, $\mathrm{CO}_{2}$ emissions, and policy costs. 


\section{System relationships drive progress across the bioeconomy.}

The BSM enables scenario exploration to support decision making highlighting interactions across systems, with nonlinearity, constant change, historical dependence, and evolving markets.
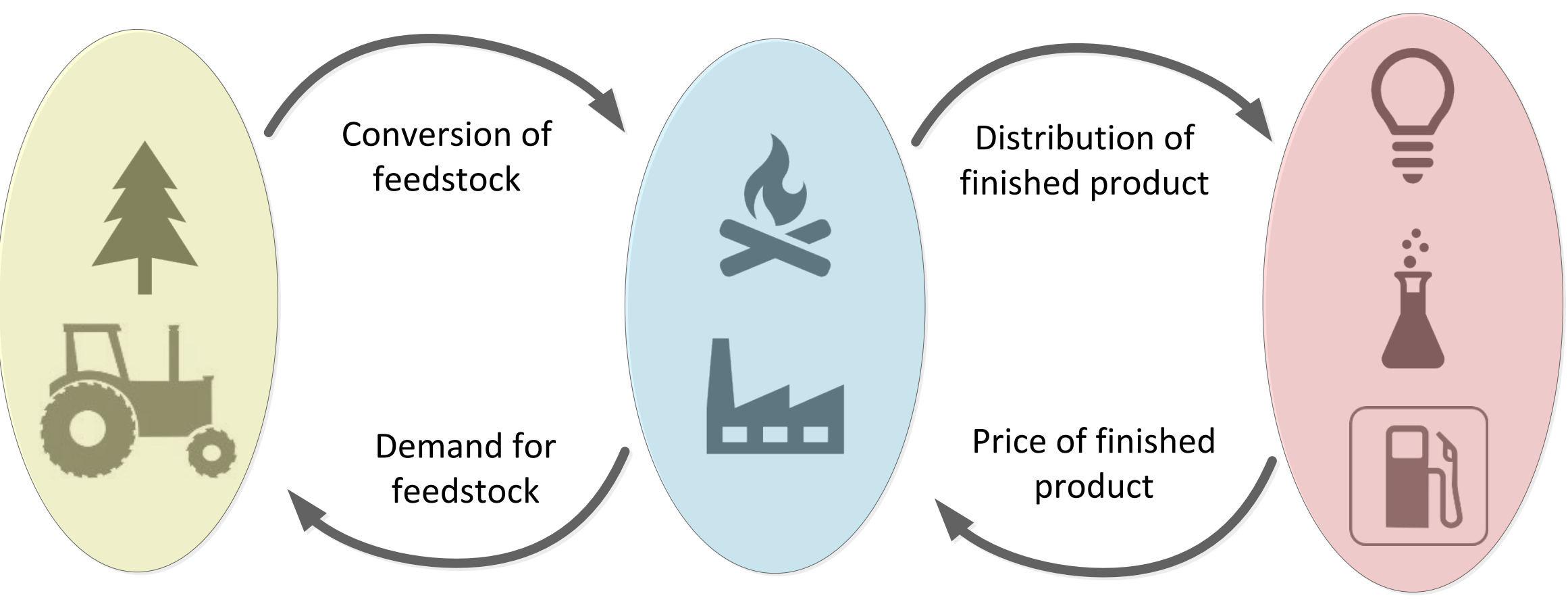

Simplistic representation of basic feedback between supply chain sectors 


\section{BSM Caveats}

BSM results should not be interpreted as predictive. Rather than magnitude, focus should be on directional impacts among different scenarios. Volumes are illustrative.

Factors other than policy can also impact market dynamics (e.g., oil prices, drought, and offtake agreements).

The BSM models various feedstock-to-conversion pathways. For this analysis we limited the pathways to only those that are currently commercially available.

The BSM has limited foresight regarding future conditions, resulting in abrupt changes when policies change.

\section{Additional Information}

- Publicly available BSM and model documentation (https://openei.org/wiki/Biomass Scenario Model)

- $\quad$ BSM publications (https://www.zotero.org/groups/209264/bsm publications/library.) 


\section{Study Design: Assumptions and Scenarios}

\section{Baseline Assumptions}

Construction Limit: 25 plants/year

Renewable Identification Numbers: \$0.7

noncellulosic, $\$ 1.7$ cellulosic to 2050

Oil Price: Annual Energy Outlook $2020^{1}$

reference

Conversion pathways maximize SAF production.

Low Carbon Fuel Standard: \$133/metric tonne

(MT) for gasoline/diesel/jet after 2020; historical values through 2020

Loan Guarantee: none

Fats, oils, and greases (FOG) supply is limited to maximum 2019 value of inedible resources.

1 “Annual Energy Outlook 2020," https://www.eia.gov/outlooks/archive/aeo20/

Reminder:

PTC $=$ Production Tax Credit

ITC = Investment Tax Credit

\section{Scenarios}

PTC: None; \$1/gal, \$1.50/gal, \$2/gal (2022 start) for 10,15 , and unlimited years ${ }^{2}$

ITC: None; Sustainable Aviation Fuel Act schedule; $30 \%, 60 \%$ (2022 start) for 10, 15, and unlimited years Carbon Tax: None, \$35/MT (2022 start)

210-year expiration means that policy is only active for 10 years; it does not signify 10 years after a facility begins production.

\section{SAF Act Schedule 3}

\begin{tabular}{|l|c|}
\hline Years & ITC Percent \\
\hline $2022-2026$ & $30 \%$ \\
\hline 2027 & $24 \%$ \\
\hline 2028 & $18 \%$ \\
\hline $2029-2034$ & $12 \%$ \\
\hline $\begin{array}{l}\text { 'Does not apply other key provisions, such as threshold on eligibility, which would } \\
\text { reduce modeled effect and cost. Introduced in the U.S. House of Representatives on } \\
\text { February 3, 2021. }\end{array}$
\end{tabular}




\section{BSM Results}




\section{Analysis Overview}

- $\quad$ PTC and ITC - individually or in combination - enable industry growth, which leads to increasing production levels even after policy expiration.

- Because FOG (fats, oils, and greases) supply is limited, cellulosic feedstock supply grows to meet industry demand.

- Production levels dip after PTC expiration then may rebound to a lower level, compared to an unlimited PTC. The dip is deeper with higher PTC values (30-60\% dip).

- At higher PTC levels and some ITC, production levels reach $20 \%$ of 2019 jet fuel consumption by 2040.*

- Modest subsidy levels are more cost-effective (more cumulative, incremental gal per cumulative $\$$ in 2050), but result in 2040 SAF production of less than $10 \%$ of 2019 jet fuel consumption.*

*Because the study scope includes only commercial technologies, these results do not estimate the potential for technology innovation to reach higher production levels. 


\section{0-Year Policy Expiration}

Higher ITC Needed for Greater Production Levels with No PTC

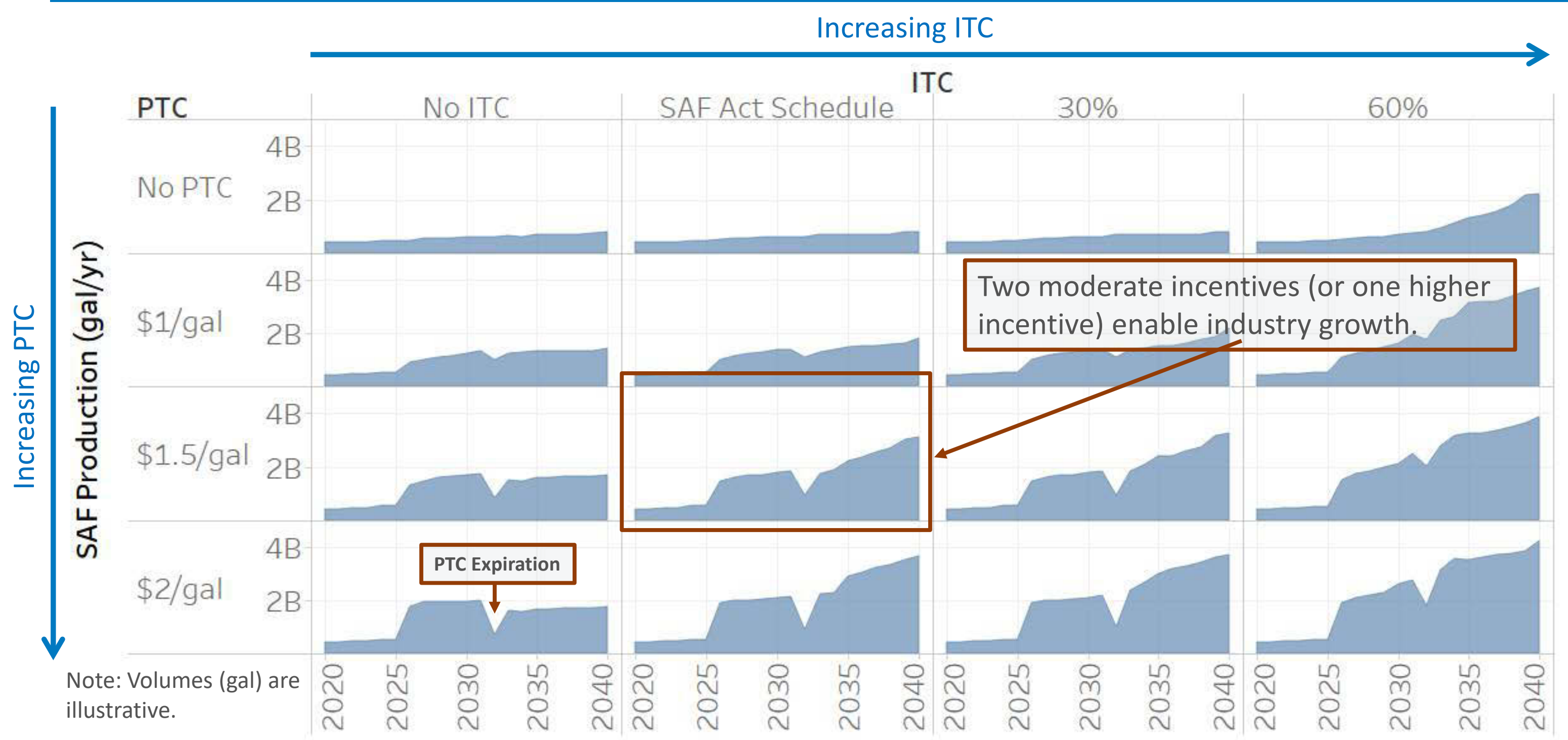




\section{5-Year Policy Expiration}

\section{Up to 25\% Increase in Production in 2040 over 10-Year Case}

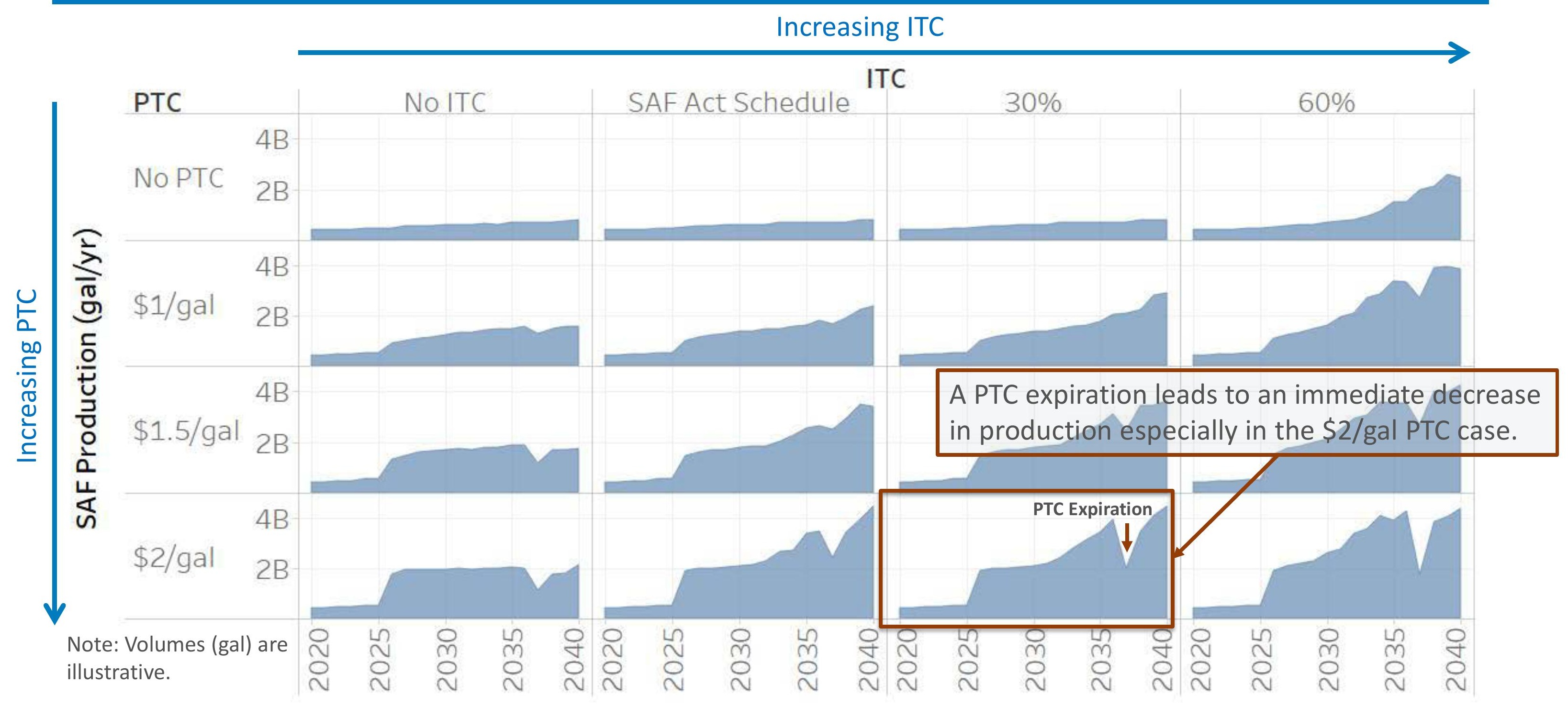




\section{Unlimited duration leads to consistently increasing production levels over time.}

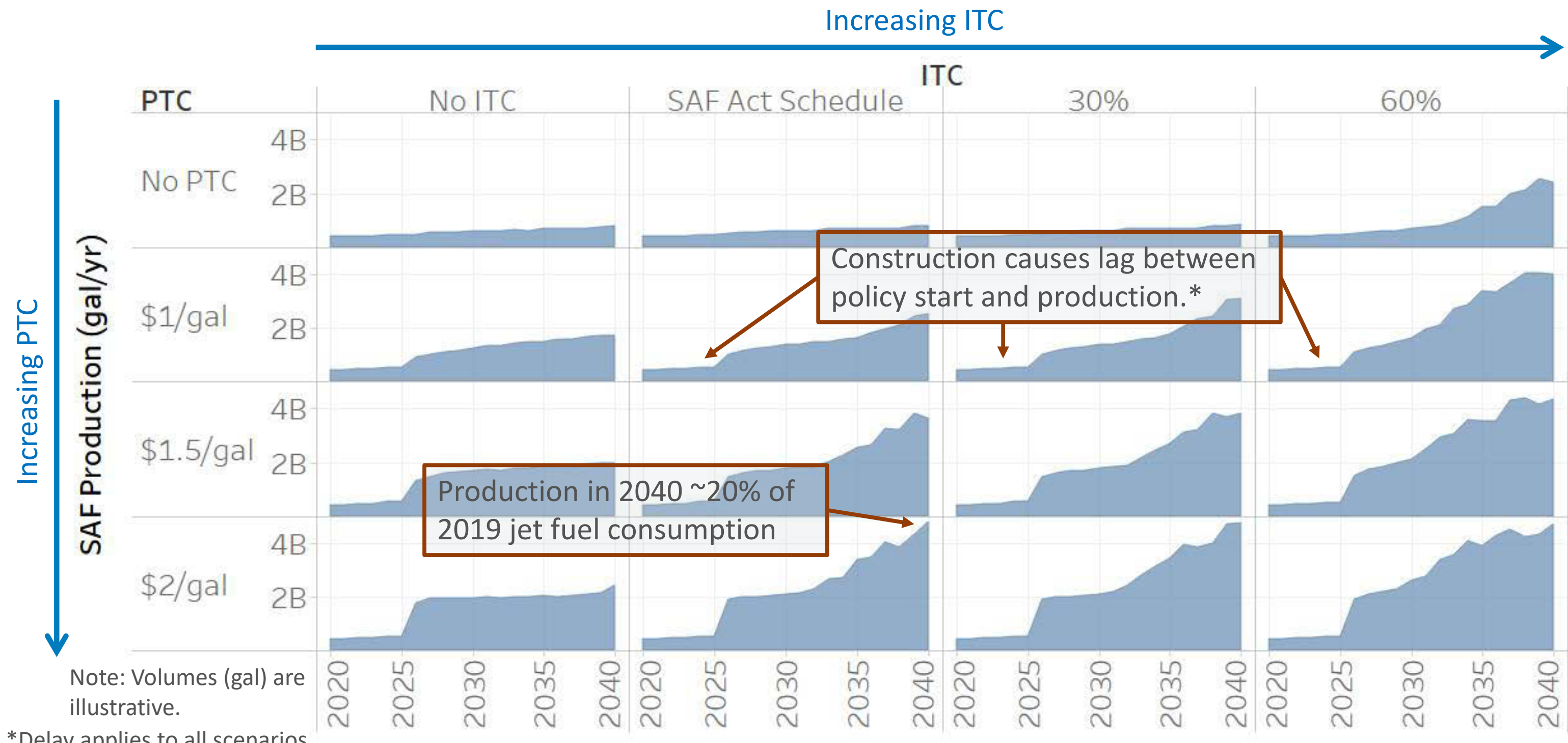

*Delay applies to all scenarios

Duration of ITC and PTC policy = unlimited (SAF ACT schedule unchanged); no carbon tax 


\section{$\$ 35 / \mathrm{MT}$ carbon tax increases production in later years.}

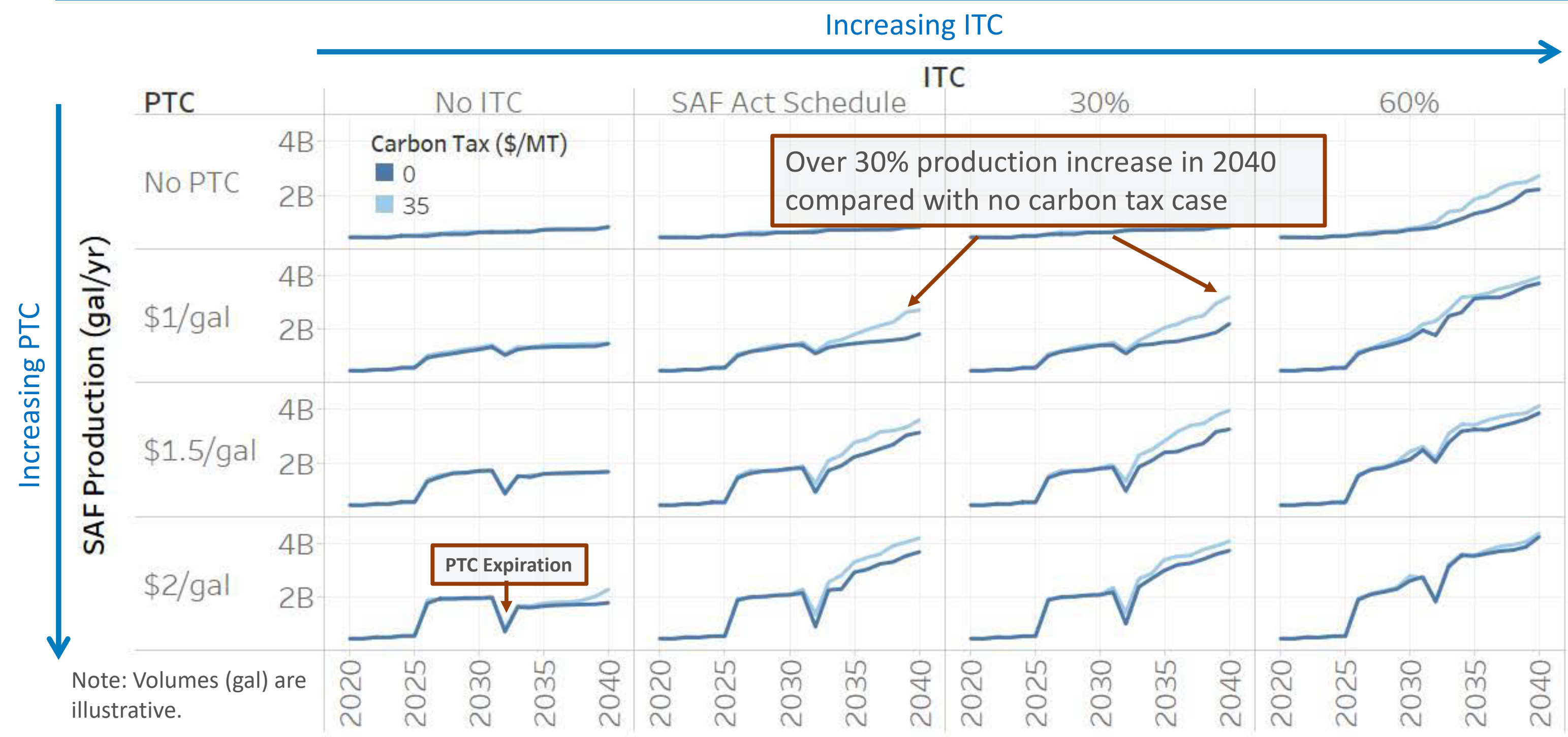




\section{Results to 2050 show production levels continue to increase.}

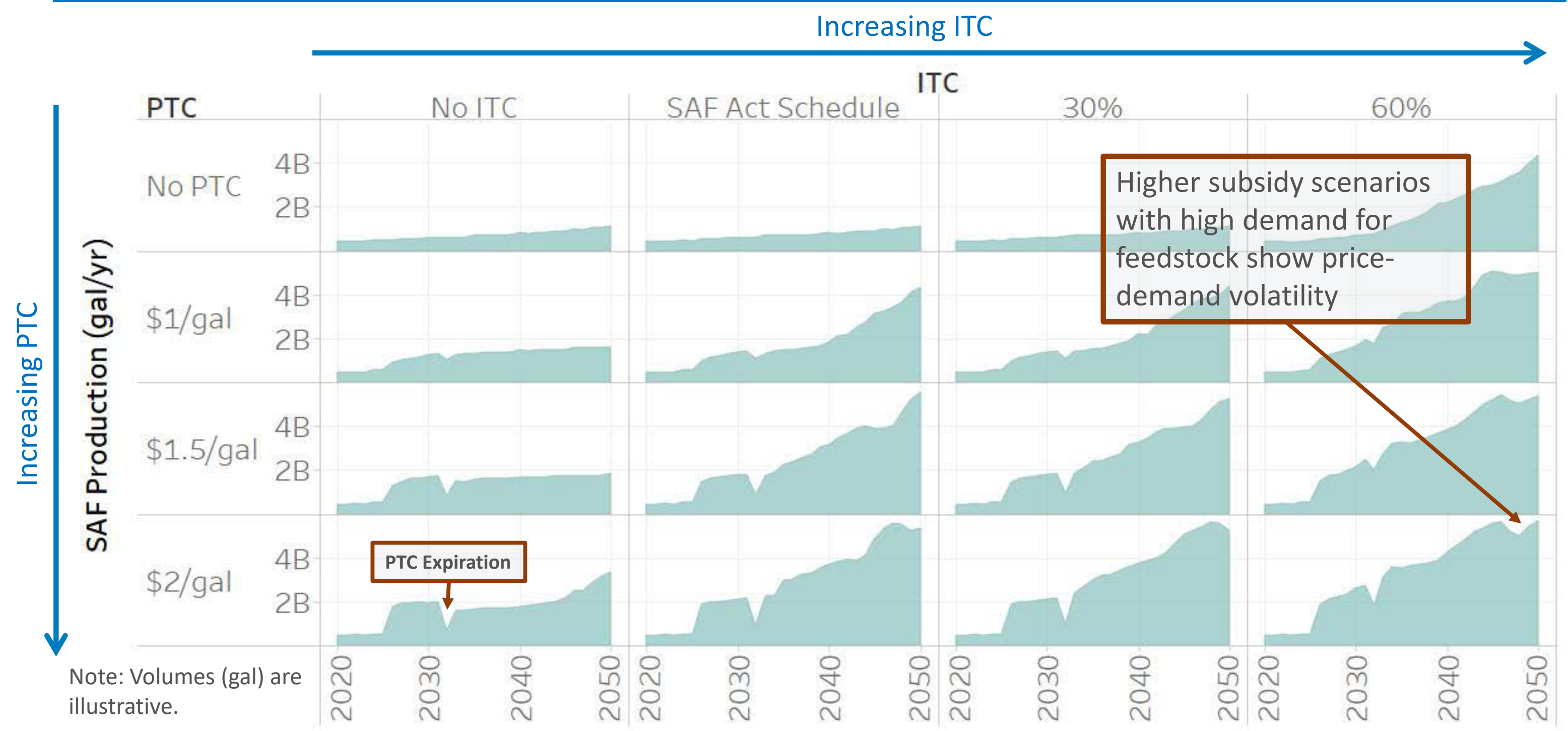




\section{Annual $\mathrm{CO}_{2}$ emissions decrease by up to 48 million MT by 2040 .}

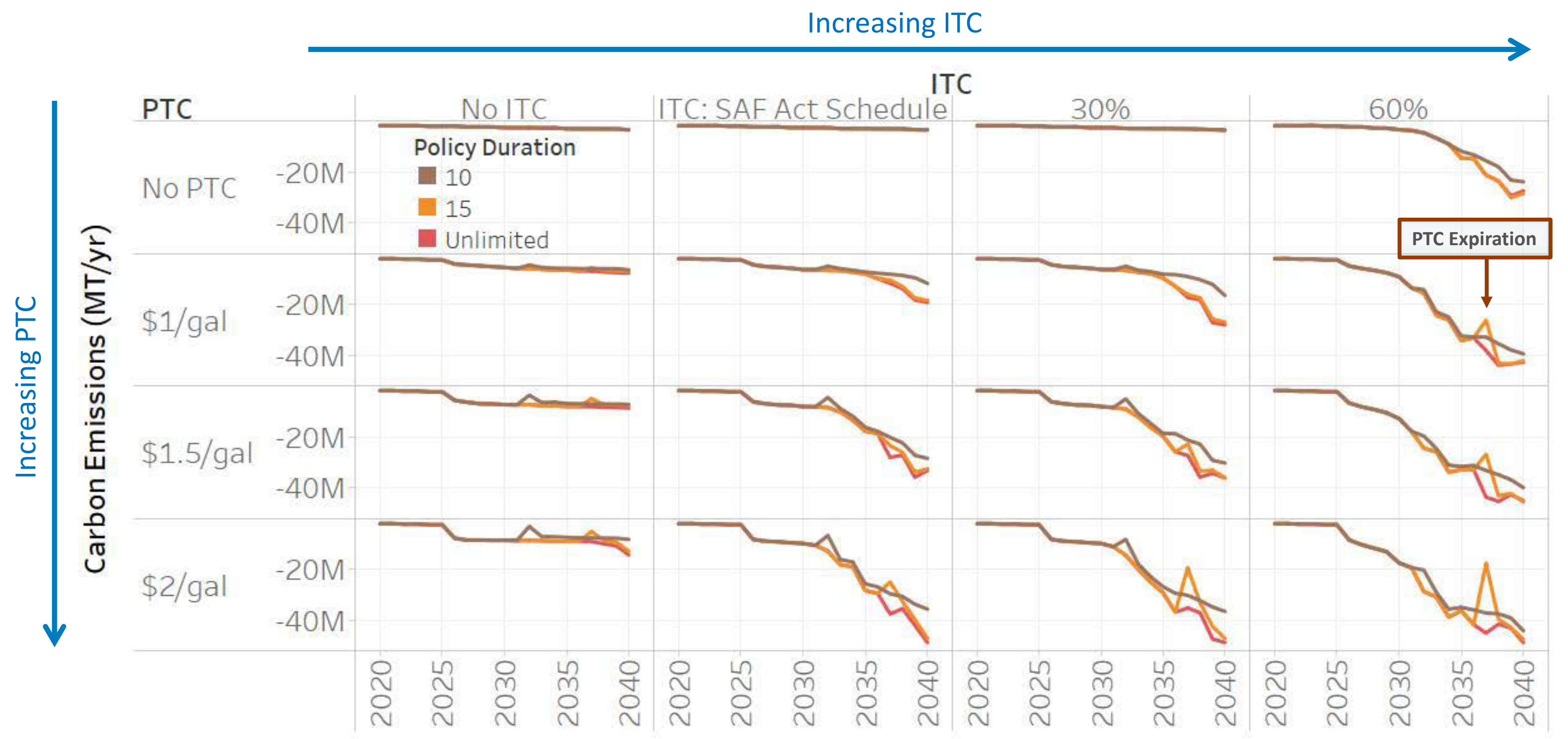


FOG supply is limited; cellulosic supply grows to meet industry demand.

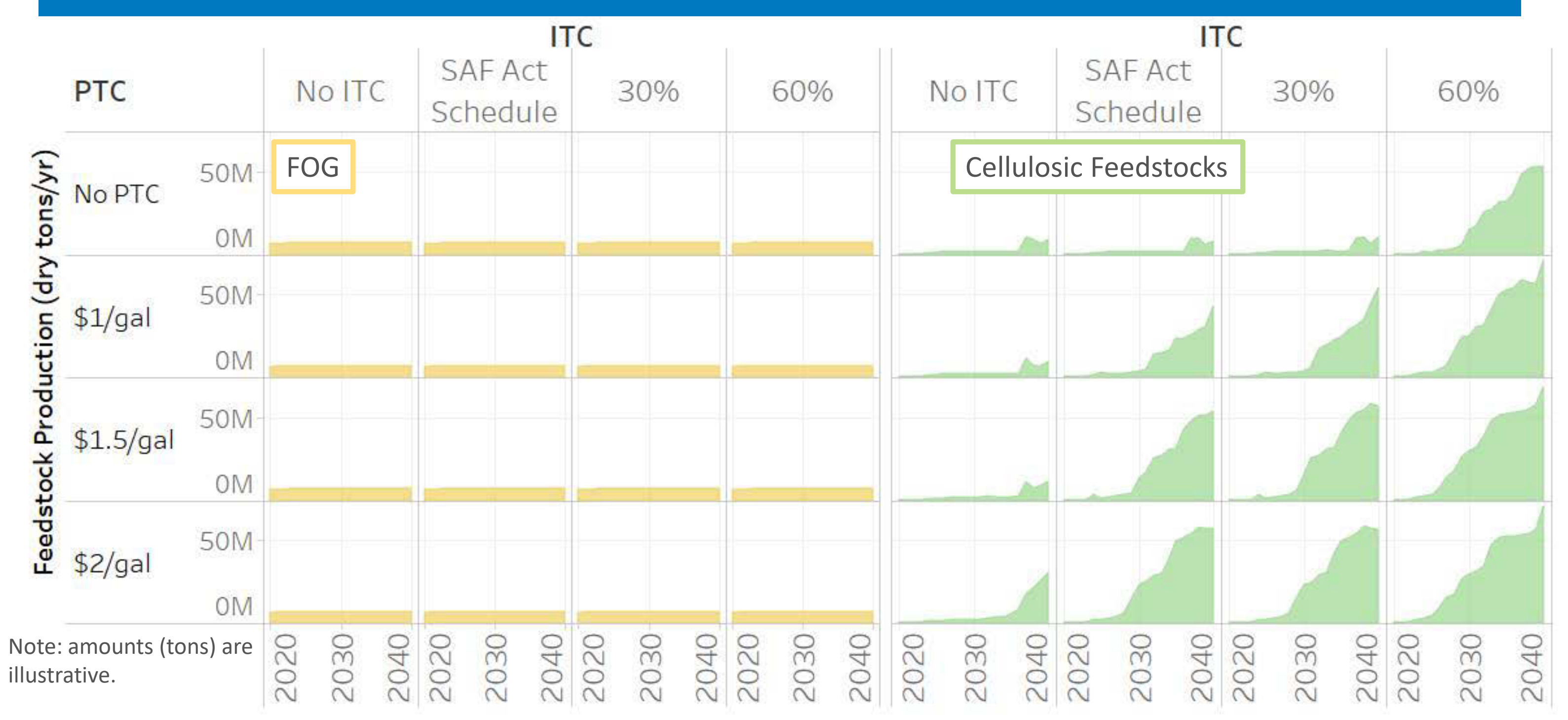


Annual cost for PTC or ITC depends on subsidy level of each policy (10 years).

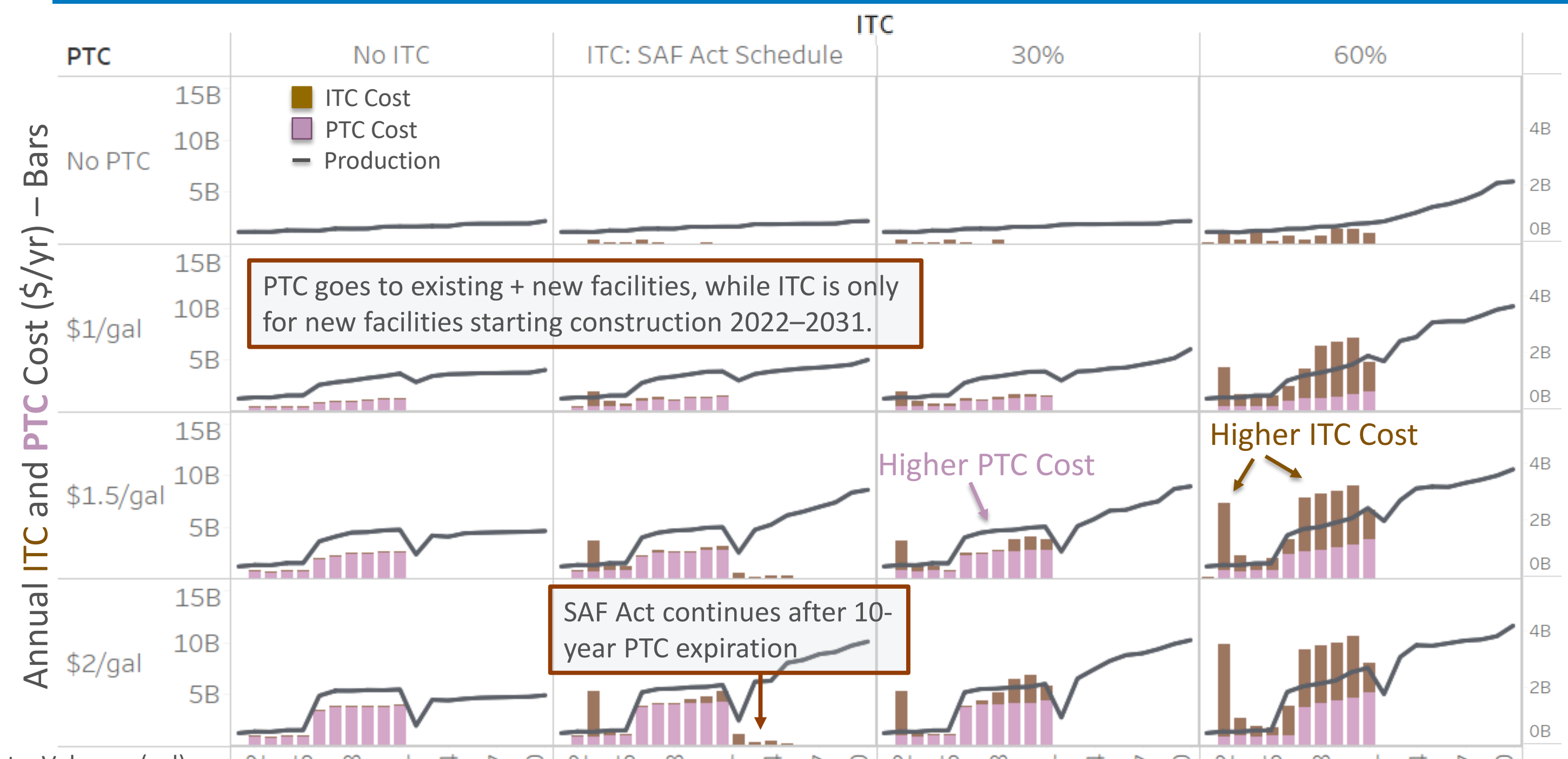

Note: Volumes (gal) are illustrative.

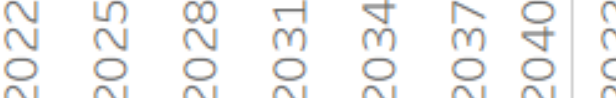

Duration of ITC and PTC policy = 10 years (SAF Act schedule unchanged); no carbon tax 
Annual cost for PTC or ITC depends on subsidy level of each policy (15 years).

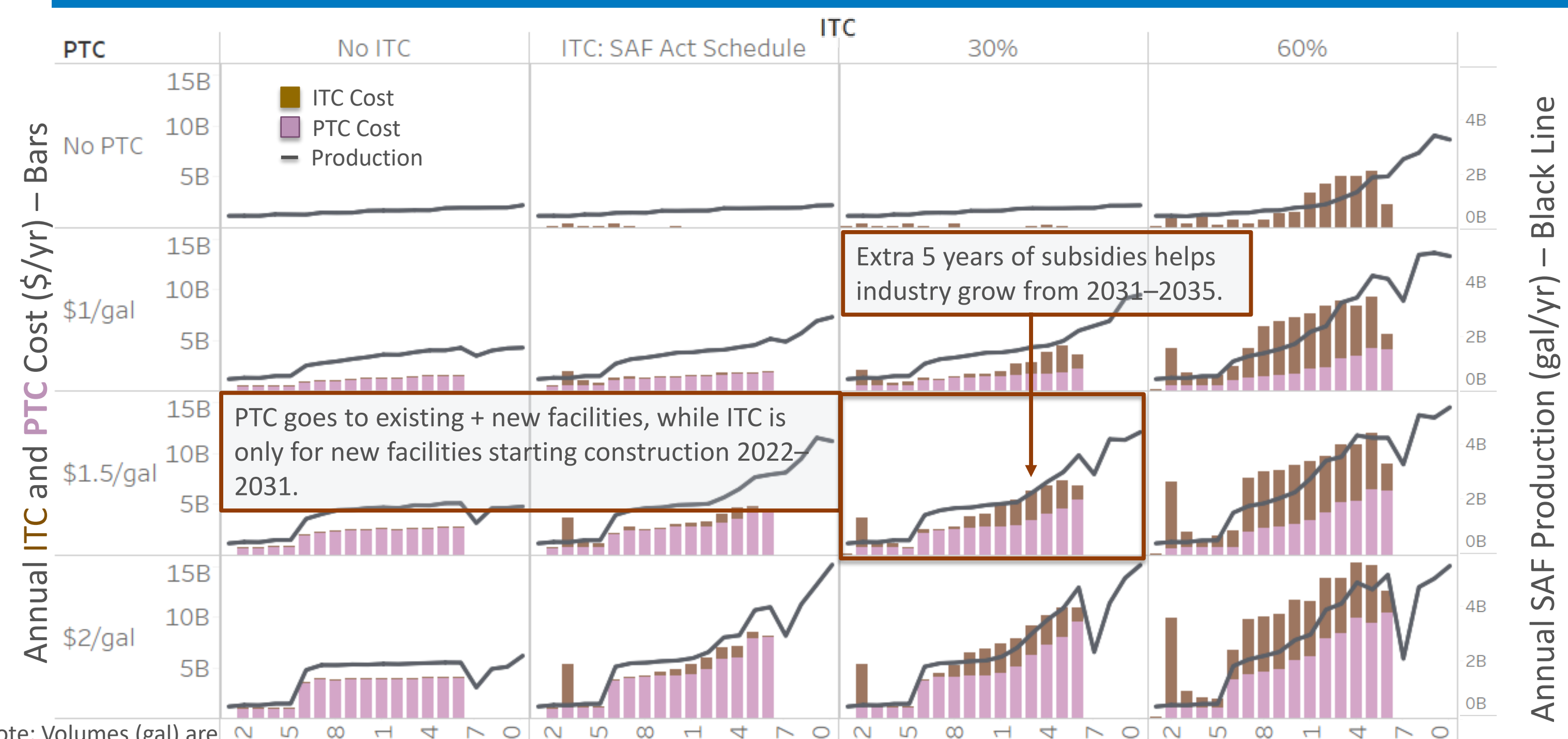

Note: Volumes (gal) are illustrative.

Duration of ITC and PTC policy = 15 years (SAF Act schedule unchanged); no carbon tax 
Cumulative cost for PTC or ITC depends on aggressiveness of each policy.

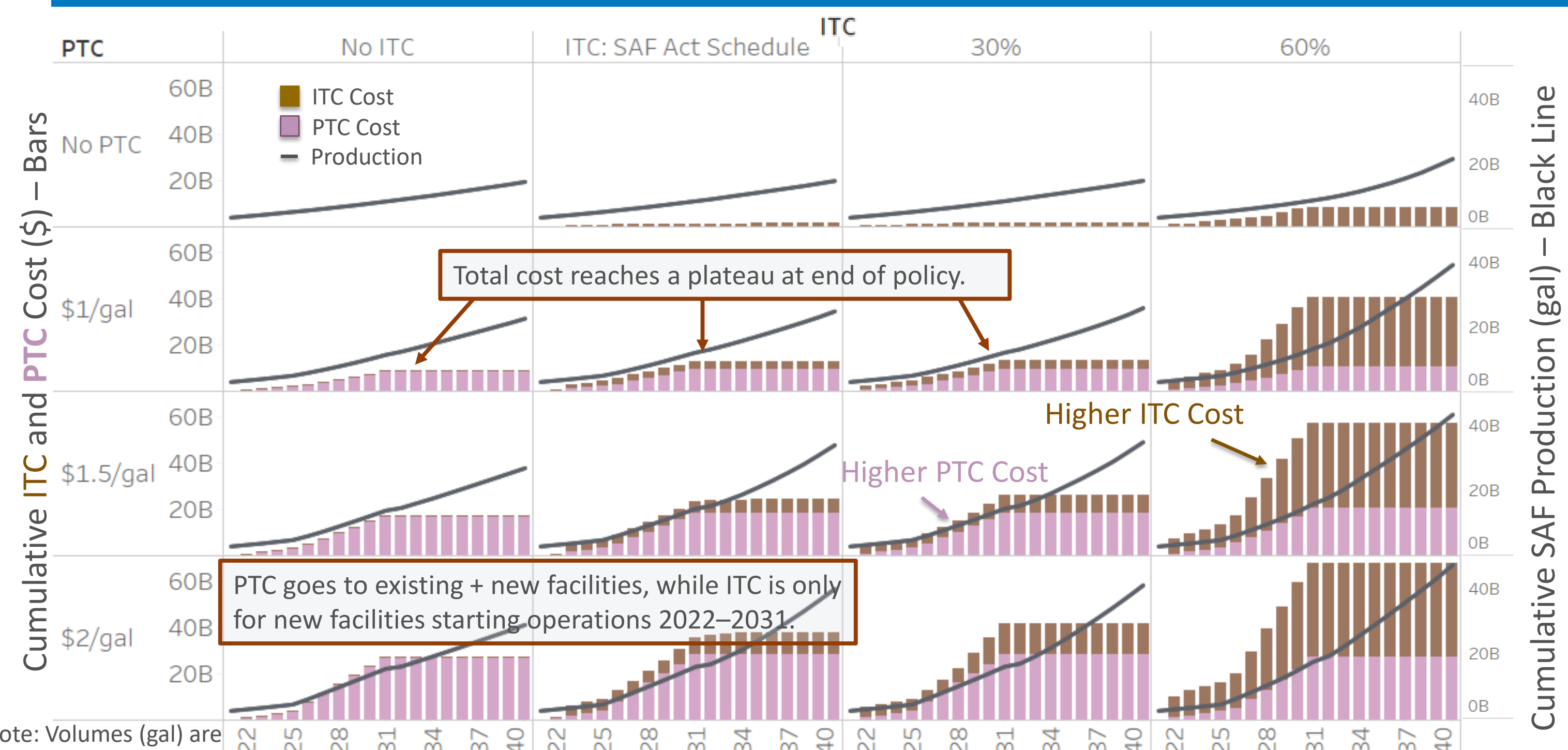
illustrative.

Duration of ITC and PTC policy = 10 years (SAF Act schedule unchanged); no carbon tax 


\section{Modest subsidy levels are more cost effective.}

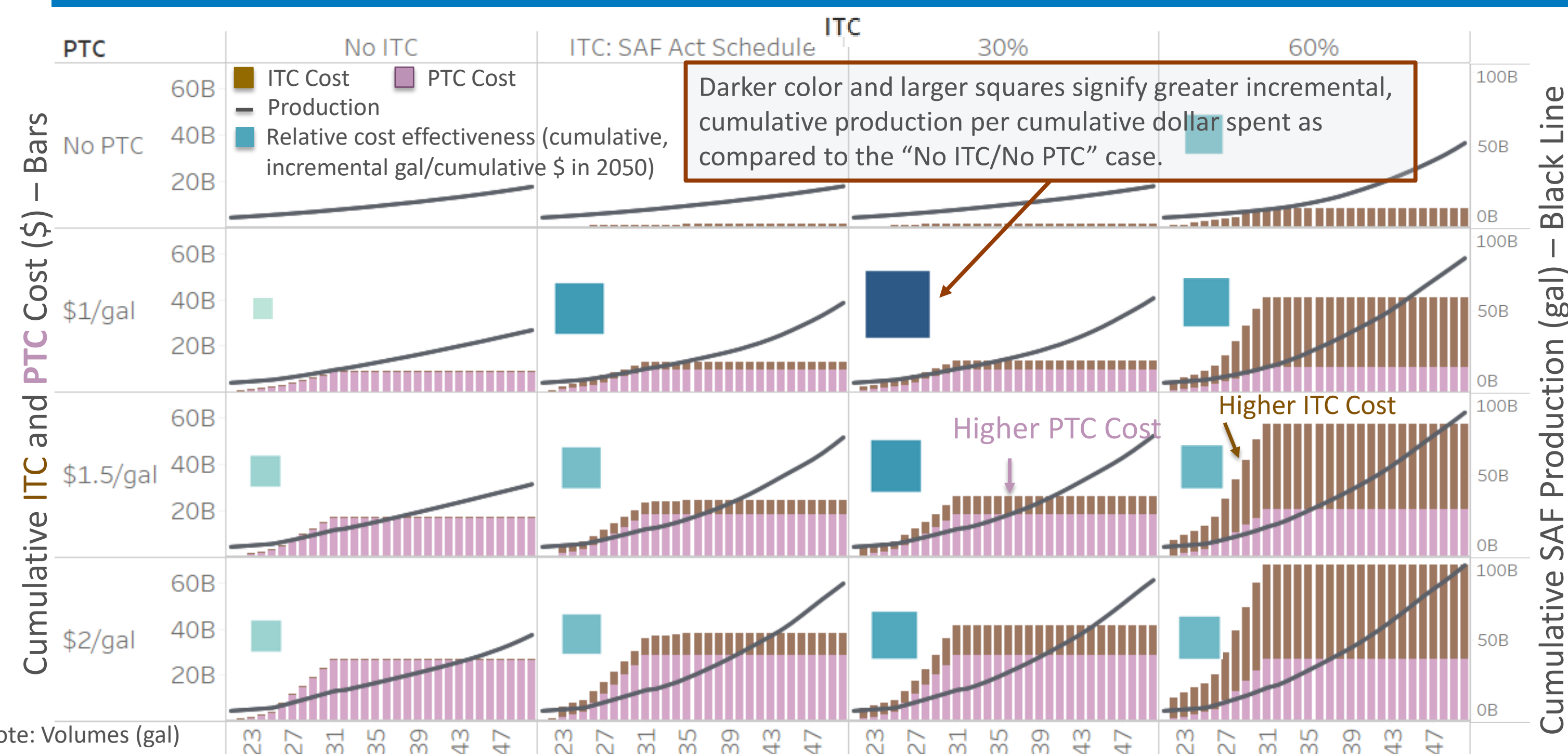

re illustrative.

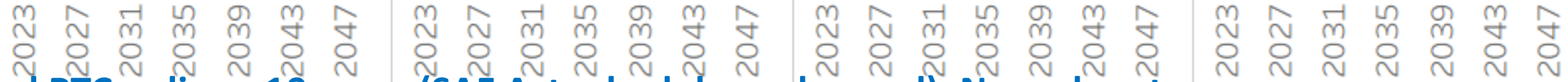

Duration of ITC and PTC policy = 10 years (SAF Act schedule unchanged); No carbon tax 


\section{Analysis Summary}

- $\quad$ PTC and ITC - individually or in combination - enable industry growth, which leads to increasing production levels even after policy expiration.

- Because FOG (fats, oils, and greases) supply is limited, cellulosic feedstock supply grows to meet industry demand.

- Production levels dip after PTC expiration then may rebound to a lower level, compared to an unlimited PTC. The dip is deeper with higher PTC values (30-60\%).

- At higher PTC levels and some ITC, production levels reach $20 \%$ of 2019 jet fuel consumption by 2040.*

- Modest subsidy levels are more cost-effective (more cumulative, incremental gal per cumulative $\$$ in 2050), but result in 2040 SAF production of less than $10 \%$ of 2019 jet fuel consumption.*

*Because the study scope includes only commercial technologies, these results do not estimate the potential for technology innovation to reach higher production levels. 


\section{Thank You}

\section{www.nrel.gov}

NREL/PR-6A20-79356

This work was authored in part by the National Renewable Energy Laboratory, operated by Alliance for Sustainable Energy, LLC, for the U.S. Department of Energy (DOE) under Contract No. DE-AC36-08G028308. Funding provided by U.S. Department of Energy Office of Energy Efficiency and Renewable Energy Bioenergy Technologies Office. The views expressed in the article do not necessarily represent the views of the DOE or the U.S. Government. The U.S. Government retains and the publisher, by accepting the article for publication, acknowledges that the U.S.

Government retains a nonexclusive, paid-up, irrevocable, worldwide license to publish or reproduce the published form of this work, or allow others to do so, for U.S. Government purposes. 


\section{Acronyms}

- AEO: Annual Energy Outlook

- BSM: Biomass Scenario Model

- DOE: U.S. Department of Energy

- E15: gasoline consisting of ethanol (nominally $15 \%$ by volume) plus petroleum-based blendstock

- FOG: fats, oils, and greases

- GHG: greenhouse gas

- HEFA: hydroprocessed esters and fatty acids

- $\quad$ ITC: investment tax credit

- $\quad$ LCFS: Low Carbon Fuel Standard

- MT: metric tonne (1,000 kilograms)

- NREL: National Renewable Energy Laboratory

- $\quad$ PTC: production tax credit

- RIN: renewable identification number

- SAF: sustainable aviation fuel

- SAF ACT: Sustainable Aviation Fuel Act 


\section{Calculation of Incremental, Cumulative Cost Metrics}

Cumulative ITC + PTC Cost $(\$)=\sum_{\text {years }}$ ITC Annual Cost + PTC Annual Cost

Base Conditions: when ITC $=0$ and PTC $=0$

Base Production: annual SAF production under case conditions

Base $\mathrm{CO}_{2}$ Emissions Reduction: annual reduction in $\mathrm{CO}_{2}$ emissions relative to petroleum fuels

Cumulative, Incremental Production (gal) $=\sum_{\text {years }}$ Annual Production - Base Production

Cost-effectiveness metric (gal/\$):

Cumulative, Incremental Production (gal)/Cumulative ITC + PTC Cost (\$) 